\title{
Ultrasound-assisted extraction of Gac (Momordica cochinchinensis Spreng.) leaves: effect of maturity stage on phytochemicals and carbohydrate-hydrolyzing enzymes inhibitory activity
}

\author{
Thi Minh Chau Nguyen", Mohsen Gavahian, ${ }^{2, *}$, Pi-Jen Tsai ${ }^{2, *}$ \\ ${ }^{1}$ International Master's Degree Program in Food Science, International College, National Pingtung University of Science \\ and Technology, 1, Shuefu Road, Neipu, Pingtung 91201, Taiwan; ${ }^{2}$ Department of Food Science, Agriculture College, \\ National Pingtung University of Science and Technology, 1, Shuefu Road, Neipu, Pingtung 91201, Taiwan
}

*Corresponding Authors: Mohsen Gavahian, National Pingtung University of Science and Technology, Taiwan, Email: mohsengavahian@yahoo.com; Pi-Jen Tsai; National Pingtung University of Science and Technology, Taiwan, Email: pijen@mail.npust.edu.tw

Received: 28 August 2020; Accepted: 12 December 2020; Published: 11 February 2021

(c) 2021 Codon Publications

OPEN ACCESS (c) () (9)

PAPER

\begin{abstract}
Although phytochemical contents of Gac fruit have been extensively analyzed, information about the bioactive compounds and valorization of Gac leaves is limited. In this study, Gac (Momordica cochinchinensis Spreng.) leaves at different maturity stages (young: YL, mature: ML and old: OL leaves) were extracted during a $20 \mathrm{~min}$ of 150-W sonication process. Color, phytochemicals, antioxidant activity, and inhibitory effects against carbohydrate-hydrolyzing enzymes were assessed by colorimetric, high-performance liquid chromatography, and spectrophotometric methods, respectively. Results indicated a decrease in L" (lightness) and an increase in a* (greenness-redness) during maturation of leaves. The YL extract had the highest contents of phytochemicals with 4897.01 (mg gallic acid equivalent [GAE] per 100 gram dried weight [DW]), total phenolics, 592.81 (mg quercetin $[\mathrm{QE}] / 100 \mathrm{~g} \mathrm{DW})$, total flavonoids, 34.77\% $\alpha$-amylase inhibitory activity, and $40.21 \% \alpha$-glucosidase inhibitory activity. Myricetin (43\%), vitexin (22\%), and esculetin (11\%) were the major bioactive compounds detected in YL extract. Also, the superoxide dismutase (SOD)-like capacity of the extract decreased from 11,599.96 to 3,999.63 U/g DW during the transformation of YL to OL. Extract of Gac leaves was found to be a potential ingredient for food preservation and supplementation that could reduce postprandial hyperglycemia.
\end{abstract}

Keywords: carbohydrate-hydrolyzing enzymes inhibitory activity; emerging processing technologies; Gac (Momordica cochinchinensis Spreng.) leaves; hyperglycemia treatment; ultrasonic-assisted extraction

\section{Introduction}

Ultrasound-assisted extraction is an innovative technique used widely for extracting bioactive compounds from plant materials (Munekata et al., 2020). Through cavitation phenomena of bubbles, ultrasound-assisted extraction can increase the permeability of plant cell walls, enhance the contact surface area between solvent and samples, and release more phenolic compounds (Moreira et al., 2019). This simple and low-cost technique has been suggested to be an alternative to the conventional extraction method, as it can save extraction time and enhance extraction efficiency (Guglielmetti et al., 2017; İşçimen et al., 2018; Karadag et al., 2019; Surin et al., 2020). This technology is used to extract Gac peel and other plant material (Chuyen et al., 2020).

Starch hydrolysis because of the activities of $\alpha$-amylase in the salivary pancreas and glands combined with $\alpha$-glucosidase in the small intestine is the main reason of blood glucose. Inhibiting the functioning of these enzymes could reduce postprandial hyperglycemia. Hence, many 
of the medicines prescribed for type II diabetes contain bioactive compounds with carbohydrate-hydrolyzing enzymes inhibitory activity (Adekola et al., 2017; Özcan, 2020). Usually, synthetic medicines taken for diabetes (e.g., voglibose, acarbose and miglitol) are good competitive inhibitors of $\alpha$-glucosidase and $\alpha$-amylase, hence inhibit patient's ability to break down complex carbohydrates into glucose. However, some side effects, including diarrhea, flatulence and abdominal discomfort, have been reported for the long-term prescription of these medicines (Mogole et al., 2020). Besides, there is a trend for replacing synthetic medicines with natural ones among the health-conscious consumers. Therefore, there is a growing market for natural medicines such as bioactive compounds extracted from plants. Moreover, some plant extracts have been suggested as a suitable source of carbohydrate hydrolase inhibitors with probably limited or no side effects (Veiga et al., 2020). For example, Dioscorea polystachya and Morus Alba have been demonstrated for their high $\alpha$-amylase and $\alpha$-glucosidase inhibitory potential, respectively; and the blends of pineapple, apple and ginger as a beverage can be used as a dietary supplement to prevent diabetes mellitus because of their hypoglycemic effects (Ademosun et al., 2020; Ng and See, 2019). The food and pharmaceutical industries are exploring the possibility of developing new anti-diabetics from other plant materials to satisfy market demand.

Belonging to the Cucurbitaceae family, Gac (Momordica Cochinchinensis Spreng.) is a perennial plant distributed widely in many regions of the world, including Northeastern Australia as well as South-East and South Asia (Chuyen et al., 2014). Gac fruit was used as a natural colorant in cuisines and was believed to improve human vision. Previous studies have demonstrated that high contents of carotenoids, lycopene and medicinal components (e.g., saponins and triterpenoids) are found in fruit, aril and seeds of Gac, respectively (Abdulqader et al., 2018; Chuyen et al., 2014; Kha et al., 2013; Yu et al., 2017). Besides, Gac leaves were consumed in traditional medicine for various purposes such as curing fever, back pain, inflammation, wart and hemorrhoids. However, information about its bioactive components and biological effects is limited. A previous study had explored carbohydrolytic enzyme inhibitory, anti-inflammatory and antioxidant abilities of other species of Momordica, that is, $M$. dioica, M. charantia, M. charantia var. muricata (Nagarani et al., 2014). However, to the best of our knowledge, there is no published paper in the scientific literature that has examined the bioactive content and possible biological effects of Gac leaves (M. cochinchinensis Spreng.). The objectives of this research were to analyze the phytochemicals available in Gac leaves and to explore their best maturity stages that could yield an extract with the highest $\alpha$-amylase and $\alpha$-glucosidase inhibitory activities.

\section{Materials and Methods}

\section{Plant materials}

The fresh Gac leaves were collected in Pingtung county, Taiwan in November 2019. The identity of the plant species (M. cochinchinensis Spreng.) was confirmed as described by experts in the literature. These leaves were divided into three different stages of maturity (YL: young; ML: mature and OL: old leaves) according to visual color and size as described in the literature (Angmo et al., 2019). The average width and length of leaves were measured using a ruler. Besides, the color values of leaves ( $\mathrm{L}^{*}$ : lightness; $a$ ": greenness-redness and $b^{*}$ : blueness-yellowness) were measured using a colorimeter (ZE 2000, Nippon Denshoku, Japan). Then, leaves were dried at $45^{\circ} \mathrm{C}$ for $48 \mathrm{~h}$ using the oven drying method (OV-100, Precision oven, HiPoint, Taiwan) until the final water activity of samples reached 0.32 (Roukas and Kotzekidou, 2020). Dried leaves were ground into powder using a pulverizing machine (RTN08, RT, Taiwan), sieved by a $0.2-0.5-\mathrm{mm}$ mesh screen to maintain constant particle size, packaged in airtight polyethylene films (0.04-mm thickness) and kept at $-4^{\circ} \mathrm{C}$ until analysis (schematic representation is presented in Figure 1).

\section{Chemicals}

Standards of phenolic and flavonoid compounds: 4-nitrophenyl $\alpha$-D-galactopyranoside (PNPG), 3,5-dinitrosalicylic acid (DNS), $\alpha$-amylase from Bacillus sp., intestinal acetone powder from rat, Folin \& Ciocalteu's phenol reagent, L-methionine, riboflavin and nitrotetrazolium blue chloride (NBT) were purchased from Sigma-Aldrich, USA. Aluminum chloride hex hydrate, dimethyl sulfoxide (DMSO), potassium acetate, potassium hydrogen phosphate, potassium dihydrogen phosphate, potassium sodium tartrate-4-hydrate, sodium acetate, sodium carbonate, sodium hydroxide and sodium hydrogen phosphate were purchased from J.T. Baker, Avantor, PA, USA. Methanol was obtained from Aencore Chemical Pvt. Ltd., Surrey Hills, Australia.

\section{Extraction procedure}

A mixture of Gac leaves powder $(1 \mathrm{~g})$ and $50 \%$ aqueous ethanol $(40 \mathrm{~mL})$ was extracted using a $150-\mathrm{W}$ ultrasonic bath (DC150, Delta, Taiwan) for $20 \mathrm{~min}$ based on preliminary studies. The temperature was monitored by a laboratory thermometer and adjusted at $25^{\circ} \mathrm{C}$. These extraction conditions were defined according to a previous study with some modifications (Tian et al., 2019). The extract was then centrifuged at 10,000 rpm for 20 min, filtered with $90-\mathrm{mm}$ filter paper and kept at $-20^{\circ} \mathrm{C}$ until further analysis. 

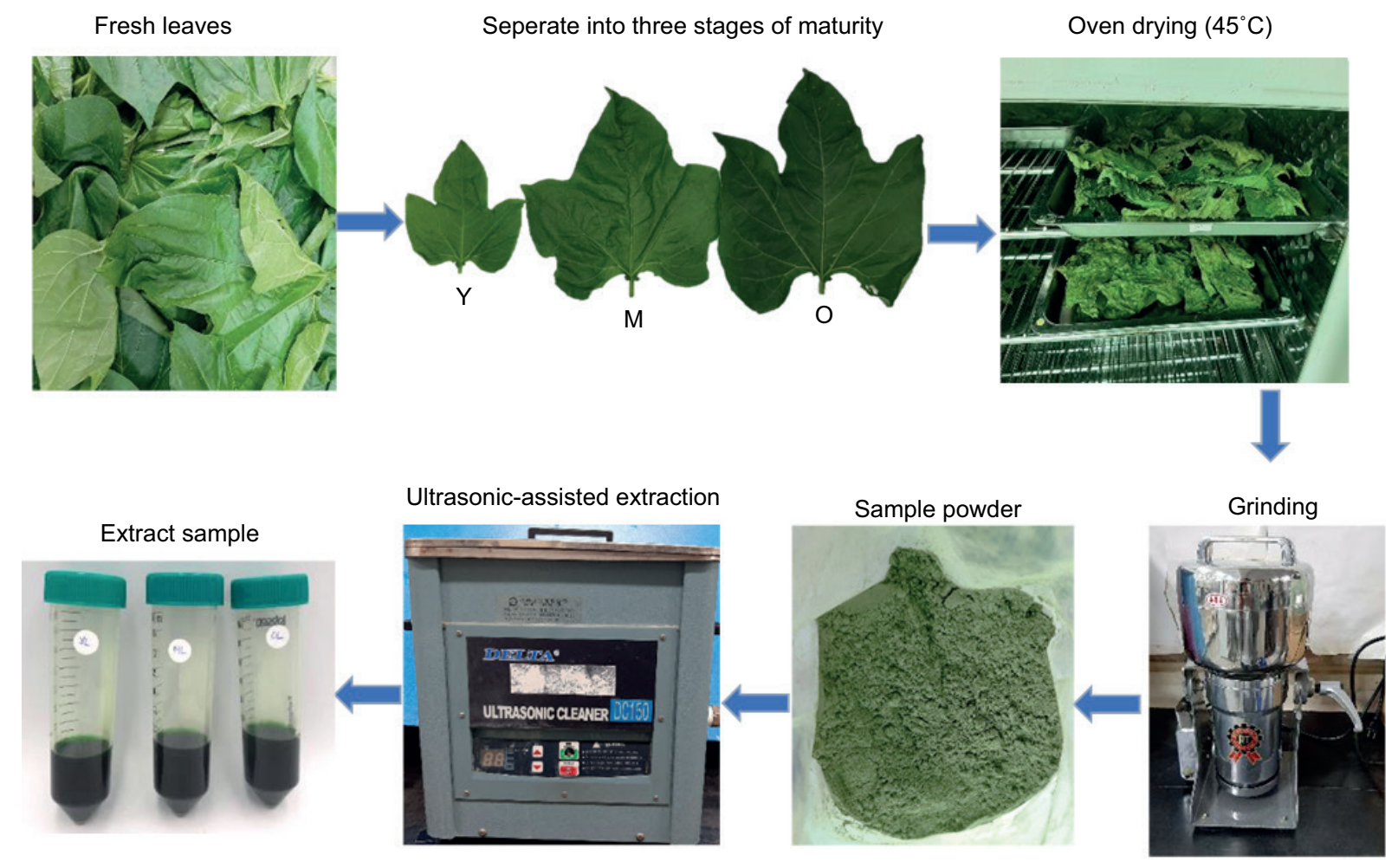

Figure 1. Schematic representation of the protocol employed to prepare Gac leaves extract. YL: young leaf; ML: mature leaf; OL: old leaf.

\section{Chemical analysis of extracts}

\section{Determination of total phenolics content}

Total phenolics content (TPC) was evaluated according to the Folin-Ciocalteu assay with minor modifications (Singleton and Rossi, 1965). A mixture of leaves extract $(0.1 \mathrm{~mL}), 50 \%$ Folin-Ciocalteu reagent $(0.1 \mathrm{~mL})$ and $2 \%$ sodium carbonate $(2 \mathrm{~mL})$ was incubated at about $25^{\circ} \mathrm{C}$ in a dark place for $30 \mathrm{~min}$. The absorbance of reactive mixture was recorded with an ultraviolet spectrophotometer (U-200 Spectrophotometer, Hitachi, Japan) at 760-nm wavelength. The TPC was measured using gallic acid calibration curve and presented as milligram gallic acid equivalent (GAE) per $100 \mathrm{~g}$ dried weight (DW) of sample (mg GAE/100 g DW).

\section{Determination of total flavonoids content}

Total flavonoids content (TFC) of Gac leaves was determined using a colorimetric method of aluminum chloride $\left(\mathrm{AlCl}_{3}\right)$ with slight modifications (Nguyen et al., 2020). An aliquot of $250 \mu \mathrm{L}$ of extracts was mixed well with $750 \mu \mathrm{L}$ of $95 \%$ ethanol, $50 \mu \mathrm{L}$ of $10 \%$ aluminum chloride, $50 \mu \mathrm{L}$ of $1 \mathrm{M}$ potassium acetate and $1.4 \mathrm{~mL}$ of distilled water in a test tube. The mixture was left for $30 \mathrm{~min}$ at room temperature in dark before recording at $415 \mathrm{~nm}$ using an ultraviolet spectrophotometer. The TFC was represented as milligram quercetin equivalent per $100 \mathrm{~g}$ dried weight sample (mg QE/100 g DW) through a QE calibration curve.

\section{Identification of phenolic and flavonoid compounds using high performance liquid chromatography}

The sample extract was filtered using a $0.45-\mu \mathrm{m}$ syringe filter (PTFE013N045I, PureTech Syringe Filter, Taiwan) before injecting it into the high-performance liquid chromatography (HPLC) system (L-7100, Hitachi, Japan). The injected extract $(20 \mu \mathrm{L})$ was then separated chromatographically on a Mightysil RP-18 column $(250 \mathrm{~mm} \times 4.6$ $\mathrm{mm}, 5 \mu \mathrm{m}$ ) (Dobrinčić et al., 2020). The mobile phases were $0.25 \%$ formic acid, $2 \%$ methanol in ultrapure water (solvent B) and 100\% methanol grade (solvent C) with a flow rate of $1 \mathrm{~mL} / \mathrm{min}$. The chromatographic peaks in extracts were identified and measured by collating their UV-visible spectra $(280 \mathrm{~nm})$ and retention period with those of external standards. The content of each polyphenol was presented as milligram per $100 \mathrm{~g}$ of dried weight sample (mg/100 g DW).

\section{Determination of $\alpha$-amylase inhibitory activity}

$\alpha$-Amylase inhibitory activity was determined based on a previous report with slight modifications (Shori, 2020). Briefly, the solvent of extract was first removed by a vacuum evaporator, the residue was then dissolved by 2 -mL $50 \%$ DMSO. Next, a mixture of this DMSO extract $(100 \mu \mathrm{L})$ and $0.5 \mathrm{U} / \mathrm{mL} \alpha$-amylase solution $(100$ $\mu \mathrm{L}$ ) was transferred in a tube and incubated at $37^{\circ} \mathrm{C}$ for 5 min. Next, $100 \mu \mathrm{L}$ of starch solution (1\%) was added and re-incubated for $5 \mathrm{~min}$ at $37^{\circ} \mathrm{C}$. The reaction ended using 
$1 \mathrm{~mL}$ of DNS color reagent, then incubated for $5 \mathrm{~min}$ in a boiling water bath and cooled down. The absorbance was read at a wavelength of $540 \mathrm{~nm}$. The background (replacing the starch by pH 6.9 buffer) and control (50\% DMSO instead of sample extract) were also prepared by the same procedure. The $\alpha$-amylase inhibitory activity was calculated according to Equation 1:

$$
\alpha \text {-amylase IA }(\%)=\frac{\mathrm{A}_{\mathrm{C}}-\left(\mathrm{A}_{\mathrm{S}}-\mathrm{A}_{\mathrm{BG}}\right)}{\mathrm{A}_{\mathrm{C}}} \times 100 \%
$$

where IA is inhibitory activity inhibitory activity, $A_{\mathrm{C}}$ is the control absorbance, $A_{\mathrm{S}}$ is the sample extract absorbance and $A_{\mathrm{BG}}$ is the background absorbance.

\section{Determination of $\alpha$-glucosidase inhibitory activity}

$\alpha$-Glucosidase inhibitory activity was determined according to a previous method with partial modifications (dos Santos Pereira et al., 2020). Before pre-incubated for $5 \mathrm{~min}$ at $37^{\circ} \mathrm{C}$, a mixture of DMSO extract $(5 \mu \mathrm{L})$ and $\alpha$-glucosidase solution $(10 \mu \mathrm{L})$ was put into a 96-well microplate. Then, 0.01-M p-nitrophenyl $\alpha$-D-galactopyranoside $(10 \mu \mathrm{L})$ was added in each well and incubated for $20 \mathrm{~min}$ at $37^{\circ} \mathrm{C}$. The mixture reaction was stopped by adding 200- $\mu \mathrm{L}$ 0.1-M sodium carbonate. The absorbance was recorded at a wavelength of $405 \mathrm{~nm}$ using a microplate reader (AMR-100, Clubio, Taiwan). Control without sample, and background without PNPG were also determined. Ability to inhibit $\alpha$-glucosidase was calculated according to Equation 2:

$$
\alpha \text {-glu cosidase IA }(\%)=\frac{\mathrm{A}_{\mathrm{C}}-\left(\mathrm{A}_{\mathrm{S}}-\mathrm{A}_{\mathrm{BG}}\right)}{\mathrm{A}_{\mathrm{C}}} \times 100 \% \text {, }
$$

where IA is inhibitory activity inhibitory activity, $A_{\mathrm{C}}$ is the control absorbance, $A_{\mathrm{S}}$ is the sample extract absorbance and $A_{\mathrm{BG}}$ is the background absorbance.

\section{Determination of superoxide dismutase-like activity}

Superoxide dismutase (SOD)-like capacity was evaluated following the previous procedure with slight modifications (Cheng et al., 2015). A volume of $2.95 \mathrm{~mL}$ of $1.67 \times 10^{-4} \mathrm{M}$ NBT and 0.01-M L-methionine was added into each tube containing $50 \mu \mathrm{L}$ of extract sample; $3 \mu \mathrm{L}$ of
$2.4 \times 10^{-6} \mathrm{M}$ riboflavin was added before transferring the test tubes into a light box and incubated for $15 \mathrm{~min}$. The blue formazan formed was read at $560 \mathrm{~nm}$. The control (buffer instead of sample) and background (riboflavin replacement buffer) were also determined. The SODlike activity (percentage of scavenging ability) was first defined by Equation 3, then measured through the SOD standard curve and represented as unit per gram dried weight sample (U/g DW).

$$
\text { Scavenging ability }(\%)=\frac{\mathrm{A}_{\mathrm{C}}-\left(\mathrm{A}_{\mathrm{S}}-\mathrm{A}_{\mathrm{BG}}\right)}{\mathrm{A}_{\mathrm{C}}} \times 100 \% \text {, }
$$

where $A_{\mathrm{C}}$ is the control absorbance, $A_{\mathrm{S}}$ is the sample extract absorbance and $A_{\mathrm{BG}}$ is the background absorbance.

Besides, the relationship between maturity level of Gac leaves and the SOD-like activity of the extract was explored using different equations to develop a mathematical model for the prediction of antioxidant activity of extract as a function of degree of maturity.

\section{Statistical analysis}

The results were presented as mean \pm standard deviation (SD) $(n=3)$. The significant difference between samples was compared by Duncan's multiple-range tests $(P<0.05)$ by one-way analysis of variance (ANOVA) using IBM SPSS statistics version 22. The correlation between phenolic compounds and the ability to inhibit carbohydrate hydrolyzed enzymes was determined using Pearson's correlation analysis with two-tailed test.

\section{Results and Discussion}

\section{Physical properties of Gac leaves at different maturity stages}

\section{Average size}

At different maturity stages of Gac leaves, the average size (width and length) was measured as represented in Table 1.

Table 1. Average size and color values of Gac leaves at different maturity stages.

\begin{tabular}{lllllll} 
& \multicolumn{2}{c}{ Average size } & & \multicolumn{3}{c}{ Color values } \\
\cline { 2 - 3 } \cline { 5 - 6 } & Width $(\mathrm{cm})$ & Length $(\mathrm{cm})$ & $\mathbf{L}^{*}$ & $\mathbf{a}^{*}$ & $\mathbf{b}^{*}$ \\
\hline YL & $7.07 \pm 0.51^{\mathrm{c}}$ & $9.63 \pm 0.70^{\mathrm{c}}$ & & $44.89 \pm 0.08^{\mathrm{a}}$ & $-7.44 \pm 0.06^{\mathrm{c}}$ & $18.08 \pm 0.09^{\mathrm{b}}$ \\
$\mathrm{ML}$ & $14.67 \pm 1.06^{\mathrm{b}}$ & $15.40 \pm 0.70^{\mathrm{b}}$ & & $42.76 \pm 0.26^{\mathrm{b}}$ & $-6.58 \pm 0.10^{\mathrm{b}}$ & $18.37 \pm 0.13^{\mathrm{a}}$ \\
OL & $16.37 \pm 0.45^{\mathrm{a}}$ & $17.57 \pm 0.31^{\mathrm{a}}$ & & $37.95 \pm 0.24^{\mathrm{c}}$ & $-6.44 \pm 0.02^{\mathrm{a}}$ & $16.14 \pm 0.09^{\mathrm{c}}$ \\
\hline
\end{tabular}

The values are presented as mean \pm standard deviation (SD) $(n=3) .{ }^{a-c}$ Values in columns with different letters indicate the significant difference $(P<0.05)$. YL: young leaf; ML: mature leaf; OL: old leaf. $L^{*}$ : lightness; $a^{*}$ : greenness--redness; $b^{*}$ : blueness-yellowness. 
It was observed that OL had the highest values of width and length (16.37 and $17.57 \mathrm{~cm}$, respectively) as compared to those of ML and YL. This suggests that the leaf size increases with development of plant and reaches the maximum limit at old stage. Similar results were demonstrated at three different maturity stages of beet leaves (Angmo et al., 2019).

\section{Color values}

The color values of Gac leaves at different maturity stages were evaluated using L", a" and b" parameters as presented in Table 1. With significant difference in samples, following color value ranges were obtained: lightness $\mathrm{L}$ (37.95-44.89), yellowness b" (16.14-18.08) and greenness a (-7.44--6.44). The decrease in $\mathrm{L}^{*}$ and increase in

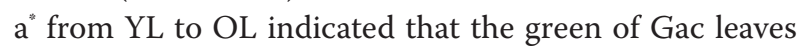
was becoming darker and browner with leaf maturation. This suggested that the plant growth could affect pigment components and color parameters in different parts of the plant. Similar observations were reported in a previous study (Patsilinakos et al., 2018).

\section{Total phenolics content and total flavonoids content}

Total phenolics content and total flavonoids content of Gac leaves at three maturing stages extracted by ultrasound-assisted extraction treatment are presented in Table 2. According to the results, the extract obtained from YL had the highest TPC and TFC values (4897.01 mg GAE/100 g DW and $592.81 \mathrm{mg}$ QE/100 g DW, respectively) followed by that of $\mathrm{ML}$ and OL. This observation indicated that the secondary metabolites (phenolics and flavonoids) are probably reduced by oxidative stress during plant growth and aging. Previous studies have established a similar trend in Coffee arabica $L$. leaves, the highest content of total phenolics was found in the extract of young leaves (Ngamsuk et al., 2019). However, the TFC expressed a slight difference in trend: it increased significantly $(P<0.05)$ from mature to old stage after decreasing from young to mature stage, that is, some new flavonoid compounds were synthesized in smaller quantities in old stage.

\section{Phytochemicals in different maturing stages}

The phytochemicals obtained from YL, ML and OL extracts are listed in Table 3. In YL extract, myricetin, vitexin and esculetin accounted for nearly 43\%, $22 \%$ and $11 \%$, respectively, of all the individual compounds detected, which were approximately 4.15, 10.62 and 2.36 times higher than that in OL extract (Figure 2). This indicated that these compounds were reduced with the aging of plant. Similarly, chlorogenic acid and vanillic acid, respectively, decreased from 339.74 and $228.56 \mathrm{mg} / 100 \mathrm{~g}$ DW in YL extract to 56.53 and $11.63 \mathrm{mg} / 100 \mathrm{~g} \mathrm{DW}$ in $\mathrm{OL}$ extract. In addition, catechin, caffeic acid and quercetin reduced by leaf senescence couldn't be detected in OL extract. This observation suggested that because of the aging process, there were notable differences in the amounts of components at different maturing stages of Gac leaves, and this was demonstrated in the guava leaf extract (Angmo et al., 2019). Results demonstrated that extract of Gac leaves contained several phenolic and flavonoid compounds that are found in the leaves of Momordica species (Nagarani et al., 2014). For example, gallic acid, chlorogenic acid, ferulic acid, quercetin, ellagic acid and catechin were identified in these Momordica leaves extract; the major components of $M$. charantia var muricata and $M$. charantia leaves were chlorogenic acid and quercetin, while $M$. dioica had rutin and ellagic acid.

Some compounds (including catechin, vanillic acid, epicatechin, chlorogenic acid and myricetin), in a previous study, have established inhibitory ability against $\alpha$-amylase and $\alpha$-glucosidase thru $\mathrm{IC}_{50}$ value with the following respective values: catechin, $8.41 \mathrm{mM}$ and 13.4 $\mu \mathrm{M}$; vanillic acid, $27.89 \mathrm{mM}$ and $277.38 \mu \mathrm{M}$; epicatechin, $7.34 \mathrm{mM}$ and $11.75 \mu \mathrm{M}$; chlorogenic acid, $11.57 \mathrm{mM}$ and $231.80 \mu \mathrm{M}$; and myricetin, $1.19 \mathrm{mM}$ and $2.73 \mu \mathrm{M}$ (Tan et al., 2017). Containing the highest levels of these compounds in the extract, YL has clearly demonstrated a strong inhibitory ability toward $\alpha$-amylase and $\alpha$-glucosidase. In addition, OL demonstrated a significant increase in ellagic acid and morin with 2.36 and 1.88 times higher than that in YL, respectively; and 3.06 and

Table 2. Phytochemicals content and carbohydrate hydrolyzing enzymes inhibitory activity at different maturity stages.

\begin{tabular}{lccccc}
$\begin{array}{l}\text { Maturing } \\
\text { stage }\end{array}$ & $\begin{array}{c}\text { TPC } \\
(\mathrm{mg} \mathrm{GAE} / 100 \mathrm{~g} \mathrm{DW})\end{array}$ & $\begin{array}{c}\text { TFC } \\
(\mathrm{mg} \mathrm{QE} / 100 \mathrm{~g} \mathrm{DW})\end{array}$ & $\begin{array}{c}\alpha \text {-amylase inhibitory } \\
\text { activity (\%) }\end{array}$ & $\begin{array}{c}\alpha \text {-glucosidase inhibitory } \\
\text { activity (\%) }\end{array}$ & $\begin{array}{c}\text { SOD-like activity } \\
\text { (Scavenging ability \%) }\end{array}$ \\
\hline YL & $4897.01 \pm 98.74^{\mathrm{a}}$ & $592.81 \pm 18.87^{\mathrm{a}}$ & $34.77 \pm 1.71^{\mathrm{a}}$ & $40.21 \pm 1.55^{\mathrm{a}}$ & $24.29 \pm 1.00^{\mathrm{a}}$ \\
ML & $4318.08 \pm 261.32^{\mathrm{b}}$ & $365.69 \pm 14.67^{\mathrm{c}}$ & $32.18 \pm 1.14^{\mathrm{b}}$ & $29.17 \pm 2.34^{\mathrm{b}}$ & $16.27 \pm 1.21^{\mathrm{b}}$ \\
OL & $3329.28 \pm 223.70^{\mathrm{c}}$ & $487.73 \pm 18.64^{\mathrm{b}}$ & $29.98 \pm 0.55^{\mathrm{b}}$ & $41.82 \pm 0.29^{\mathrm{a}}$ & $10.15 \pm 1.71^{\mathrm{c}}$ \\
\hline
\end{tabular}

The results are presented as mean \pm standard deviation $(S D)(n=3) .{ }^{a-c}$ n the same column, different letters express remarkable difference between samples $(P<0.05)$, Duncan's test. YL: young leaf; ML: mature leaf; OL: old leaf; TPC: total phenolic content; TFC: total flavonoid content; GAE: gallic acid equivalent; DW: dry weight; QE: quercetin. 
Table 3. Concentrations of total phenolic and flavonoid compounds at different maturity stages.

\begin{tabular}{|c|c|c|c|c|}
\hline Compounds & $\begin{array}{l}\text { Chemical } \\
\text { formula }\end{array}$ & $\begin{array}{c}\text { OL } \\
(\mathrm{mg} / 100 \mathrm{~g} \mathrm{DW})\end{array}$ & $\begin{array}{c}\mathrm{ML} \\
(\mathrm{mg} / 100 \mathrm{~g} \mathrm{DW})\end{array}$ & $\begin{array}{c}\mathrm{YL} \\
(\mathrm{mg} / 100 \mathrm{~g} \mathrm{DW})\end{array}$ \\
\hline Esculetin & $\mathrm{C}_{9} \mathrm{H}_{6} \mathrm{O}_{4}$ & $227.41 \pm 39.28^{\mathrm{cB}}$ & $320.02 \pm 61.72^{\mathrm{bB}}$ & $537.29 \pm 46.95^{\mathrm{cA}}$ \\
\hline Catechin & $\mathrm{C}_{15} \mathrm{H}_{14} \mathrm{O}_{6}$ & ND & $25.08 \pm 3.64^{\mathrm{eB}}$ & $66.14 \pm 3.07^{\mathrm{ghA}}$ \\
\hline Chlorogenic acid & $\mathrm{C}_{16} \mathrm{H}_{18} \mathrm{O}_{9}$ & $56.53 \pm 5.07^{\mathrm{fgC}}$ & $151.55 \pm 21.57^{\mathrm{dB}}$ & $339.74 \pm 41.25^{\mathrm{dA}}$ \\
\hline Vanillic acid & $\mathrm{C}_{8} \mathrm{H}_{8} \mathrm{O}_{4}$ & $11.63 \pm 0.67^{\mathrm{hC}}$ & $39.22 \pm 9.50^{d B}$ & $228.56 \pm 11.85^{\mathrm{eA}}$ \\
\hline Caffeic acid & $\mathrm{C}_{9} \mathrm{H}_{8} \mathrm{O}_{4}$ & ND & $1.42 \pm 0.16^{\mathrm{eB}}$ & $2.24 \pm 0.50^{\mathrm{hA}}$ \\
\hline Epicatechin & $\mathrm{C}_{15} \mathrm{H}_{14} \mathrm{O}_{6}$ & $28.34 \pm 1.99^{g h B}$ & $23.25 \pm 4.09^{\mathrm{eB}}$ & $46.06 \pm 5.00^{\mathrm{ghA}}$ \\
\hline$p$-coumaric acid & $\mathrm{C}_{9} \mathrm{H}_{8} \mathrm{O}_{3}$ & $22.26 \pm 2.85^{g h B}$ & $24.29 \pm 2.45^{\mathrm{eB}}$ & $51.97 \pm 1.82^{\mathrm{ghA}}$ \\
\hline Sinapic acid & $\mathrm{C}_{11} \mathrm{H}_{12} \mathrm{O}_{5}$ & $10.77 \pm 0.92^{\mathrm{hC}}$ & $31.93 \pm 3.26^{\mathrm{eB}}$ & $88.16 \pm 11.01^{\mathrm{fg} A}$ \\
\hline Ferulic acid & $\mathrm{C}_{10} \mathrm{H}_{10} \mathrm{O}_{4}$ & $10.61 \pm 1.75^{\mathrm{hC}}$ & $26.23 \pm 2.00^{\mathrm{eB}}$ & $62.56 \pm 4.11^{\mathrm{ghA}}$ \\
\hline Vitexin & $\mathrm{C}_{21} \mathrm{H}_{20} \mathrm{O}_{10}$ & $104.91 \pm 23.36^{\mathrm{deC}}$ & $247.20 \pm 17.31^{\mathrm{CB}}$ & $1114.31 \pm 135.69^{\mathrm{bA}}$ \\
\hline Ethyl 3,4-dihydroxybenzoate & $\mathrm{C}_{9} \mathrm{H}_{10} \mathrm{O}_{4}$ & $71.91 \pm 11.33^{\mathrm{ef}}$ & ND & ND \\
\hline Rutin & $\mathrm{C}_{27} \mathrm{H}_{30} \mathrm{O}_{16}$ & $16.70 \pm 1.90^{\mathrm{hA}}$ & $5.17 \pm 0.40^{\mathrm{eB}}$ & $1.90 \pm 0.35^{\mathrm{hC}}$ \\
\hline Resveratrol & $\mathrm{C}_{14} \mathrm{H}_{12} \mathrm{O}_{3}$ & ND & ND & $1.74 \pm 0.36^{h}$ \\
\hline Ellagic acid & $\mathrm{C}_{14} \mathrm{H}_{6} \mathrm{O}_{8}$ & $364.71 \pm 48.92^{\mathrm{bA}}$ & $118.85 \pm 9.96^{d C}$ & $154.51 \pm 4.99^{\mathrm{fB}}$ \\
\hline Myricetin & $\mathrm{C}_{15} \mathrm{H}_{10} \mathrm{O}_{8}$ & $530.73 \pm 58.48^{\mathrm{aC}}$ & $968.44 \pm 95.50^{\mathrm{aB}}$ & $2203.48 \pm 118.71^{\mathrm{aA}}$ \\
\hline Morin & $\mathrm{C}_{15} \mathrm{H}_{10} \mathrm{O}_{7}$ & $138.26 \pm 19.50^{d A}$ & $32.45 \pm 6.98^{\mathrm{eC}}$ & $73.64 \pm 4.17^{\mathrm{ghB}}$ \\
\hline Cinnamic acid & $\mathrm{C}_{9} \mathrm{H}_{8} \mathrm{O}_{2}$ & $4.38 \pm 0.57^{\mathrm{hC}}$ & $14.26 \pm 2.61^{\mathrm{eB}}$ & $17.98 \pm 0.46^{\mathrm{ghA}}$ \\
\hline Quercetin & $\mathrm{C}_{15} \mathrm{H}_{10} \mathrm{O}_{7}$ & ND & $11.19 \pm 2.49^{\mathrm{eB}}$ & $52.53 \pm 3.62^{\mathrm{ghA}}$ \\
\hline Hesperidin & $\mathrm{C}_{28} \mathrm{H}_{34} \mathrm{O}_{15}$ & $0.63 \pm 0.16^{h}$ & ND & ND \\
\hline
\end{tabular}

The values are presented as mean \pm standard deviation (SD) $(n=3)$. ${ }^{\text {ah }}$ Values in columns with different lowercase letters indicate the significant difference $(P<0.05) .{ }^{A-C}$ Values in rows with different uppercase letters indicate the significant difference $(P<0.05)$. ND: not detected. YL: young leaf; ML: mature leaf; OL: old leaf; DW: dry weight.

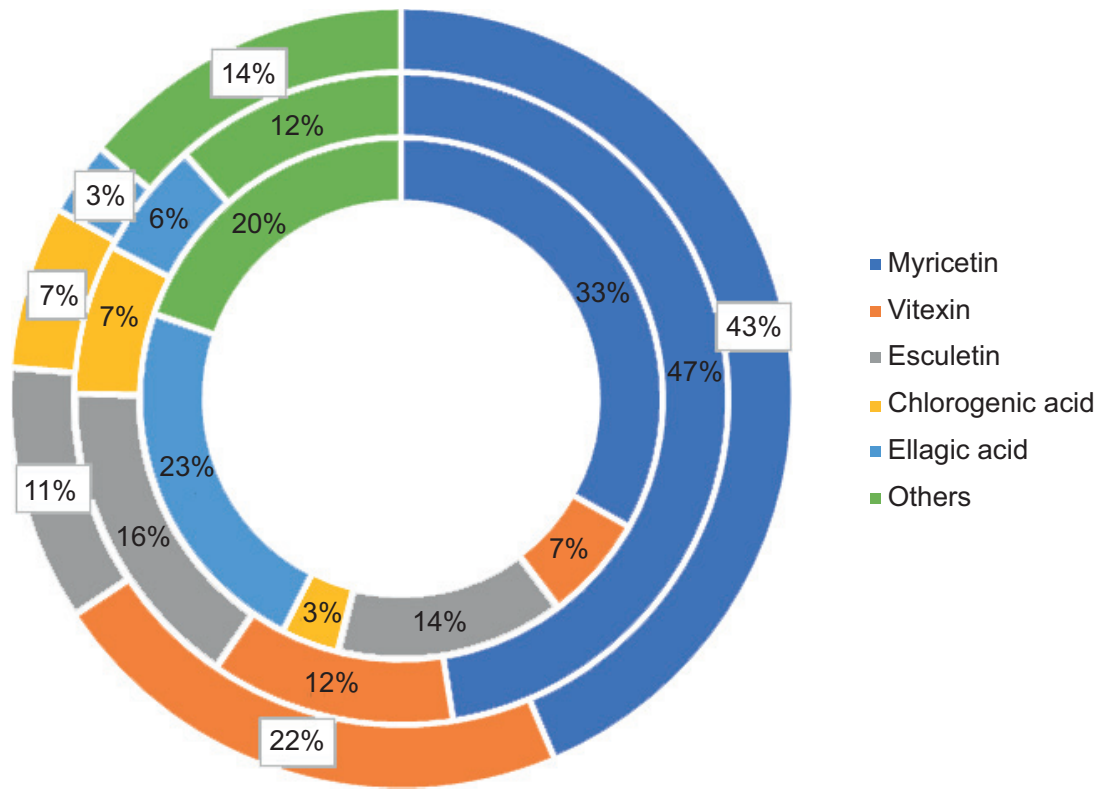

Figure 2. Main components of Gac leaves extract as affected by maturity stages. YL (young leaf), ML (mature leaf), and OL (old leaf) are presented in the inner, middle, and outer graphs, respectively. 
4.26 times higher than that in $\mathrm{ML}$, respectively. With a low $\mathrm{IC}_{50}$ value (morin: $32 \mu \mathrm{M}$, ellagic acid: $18.4 \mu \mathrm{g} / \mathrm{mL}$ ) (Assefa et al., 2020; Proença et al., 2017), the increase of these two compounds may explain a higher inhibition of $\alpha$-glucosidase in OL extract. According to the results, YL samples present the best maturing stage of Gac leaves for obtaining the highest concentration of bioactive compounds and the strongest inhibition of carbohydrate-hydrolyzing enzymes for further experiments.

\section{Effects on carbohydrate-hydrolyzing enzymes' inhibitory activity}

For the starch hydrolysis enzymes' inhibitory activity, the effects of maturing stages of Gac leaves presented the same tendency with the content of phytochemicals (Table 2). The higher $\alpha$-amylase and $\alpha$-glucosidase inhibitory abilities belonged to YL extract (34.77 and 40.20\%, respectively), which is probably because of higher concentrations of most phenolic and flavonoid components in YL. It has been explained previously, how flavonoid compounds could contribute in lowering the blood sugar and what are the mechanisms involved in their antidiabetic properties (AL-Ishaq et al., 2019). The results demonstrated that Gac leaves contain bioactive compounds that could lower the blood sugar, and the concentration of these compounds varies depending on the maturity stage of Gac leaves. This indicates the importance of effective compounds in lowering the blood sugar level, and this study established that such an extract and its effective components could be established as possible ingredients for developing nutritional supplements.

The results of the present study were similar to those reported for extracts obtained from the leaves of Momordica charantia Linn and Momordica charanti var. muricata (with an approximate $\alpha$-amylase inhibition of $45 \%$ and $\alpha$-glucosidase inhibition of $40 \%$, respectively) (Nagarani et al., 2014). Besides, previous research done on Ceylon cinnamon leaves demonstrated a similar trend, that is, higher concentrations of polyphenolic compounds were correlated with stronger anti-amylase activity (Abeysekera et al., 2019). However, the anti-glucosidase activity obtained from YL and OL extracts was almost the same in spite of significant difference in TPC and TFC, suggesting that several new compounds (e.g., ethyl 3,4-dihydroxybenzoate and hesperidin) were synthesized in the old stage of Gac leaves.

\section{Effects on SOD scavenging activity}

Superoxide dismutase, an important antioxidant enzyme in animals and plants, is a free radical scavenger that transformed reactive oxygen species formed during

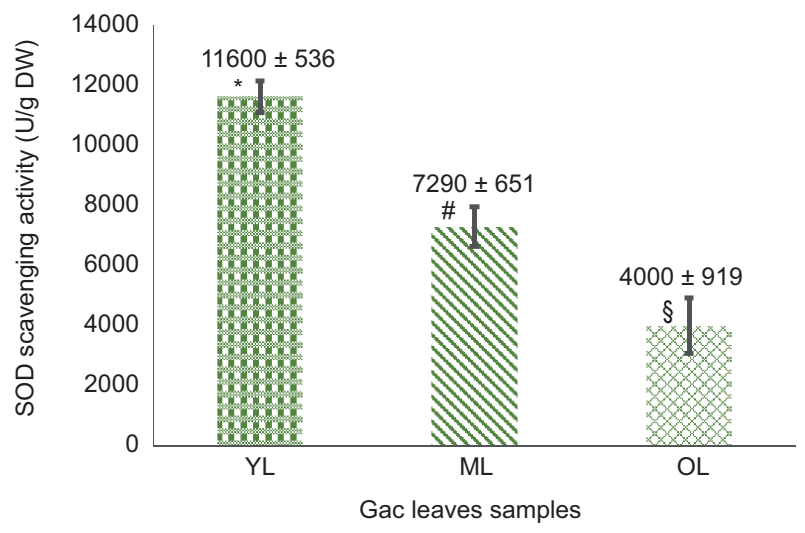

Figure 3. Superoxide dismutase (SOD) scavenging activity of the extract as affected by maturation degree of Gac leaves. YL: young leaf; ML: mature leaf; OL: old leaf.

reduction and oxidation into $\mathrm{H}_{2} \mathrm{O}_{2}$ and $\mathrm{O}_{2}$ (Cheng et al., 2015; Stephenie et al., 2020). SOD activity at different maturity stages of Gac leaves is presented in Table 2. The data ranged from $10.15 \%$ to $24.29 \%$ of free radical scavenging activity of SOD (equivalent to 3999.63-11599.96 U/g DW), which presented the same result with $M$. charantia Linn. leaf extract (22\%) but lower than that of $M$. charantia var. muricata and $M$. dioica leaf extracts, that is, 35\% and $51 \%$, respectively (Nagarani et al., 2014). Besides, the highest SOD level was achieved from YL extract $(11599.96 \mathrm{U} / \mathrm{g}$ DW), followed by ML and OL (7289.70 and $3999.63 \mathrm{U} / \mathrm{g}$ DW, respectively) (Figure 3$)(P<0.05)$. This demonstrates a similar trend with the content of phytochemicals and carbohydrate hydrolyzing enzyme inhibitory activity. The high correlation between them has been proved in a previous study (Shimada et al., 2020). For example, a previous study explained the association between anti-glucosidase ability and SOD-like activity (correlation coefficient: 0.72), and between total soluble phenolic content and SOD-like activity (correlation coefficient: 0.71 ).

According to Figure 3, the SOD scavenging activity of Gac leaves extract depended on the degree of maturity, which declined with the aging of leaves. A polynomial model was developed, which well predicted $\left(\mathrm{R}^{2}=1\right)$ the changes in the SOD scavenging activity of Gac leaf extract (Equation 4):

$$
y=675.87 x^{2}-6337.9 x+17
$$

where $y$ is the SOD scavenging activity of the extract in $\mathrm{U} / \mathrm{g} \mathrm{DW}$ and $x^{2}$ is the degree of maturity of Gac leaves $(\mathrm{YL}=1, \mathrm{ML}=2$ and $\mathrm{OL}=3)$.

\section{Conclusion}

For the first time, bioactive compounds of Gac leaves were extracted and analyzed whereas previous research 
had primarily focused on the fruit of this plant. The Gac leaves extract was found to be rich in phenolics and flavonoids. Relatively high concentrations of compounds, such as myricetin, vitexin, esculetin, chlorogenic acid and vanillic acid, suggested that this plant extract is a source of valuable bioactive compounds. It was demonstrated that the degrees of maturity can significantly affect the chemical composition and carbohydrate-hydrolyzing enzymes inhibitory activity of Gac leaves. Young leaves were found to be superior to others in terms of quantity and quality of phytochemicals because of the highest concentration of most compounds obtained, and they possess the strongest ability in inhibiting $\alpha$-amylase and $\alpha$-glucosidase. Therefore, Gac leaves have the potential to be used as an ingredient of functional foods, nutritional supplements and pharmaceuticals because of the benefits such as lowering hyperglycemia and antioxidant properties. Additional pharmacological research is needed for its use in the treatment of diabetes.

\section{References}

Abdulqader, A., Ali, F., Ismail, A. and Esa, N., 2018. Gac (Momordica cochinchinensis Spreng.) fruit and its potentiality and superiority in health benefits. Journal of Contemporary Medical Sciences 4(4). 179-186.

Abeysekera, W.P.K.M., Arachchige, S.P.G., Abeysekera, W.K.S.M., Ratnasooriya, W.D. and Medawatta, H.M.U.I. (2019). Antioxidant and glycemic regulatory properties potential of different maturity stages of leaf of Ceylon Cinnamon (Cinnamomum zeylanicum Blume) in vitro. Evidence-Based Complementary and Alternative Medicine, 2019. https://doi. org/10.1155/2019/2693795

Adekola, K.A., Salleh, A.B., Zaidan, U.H., Azlan, A., Chiavaro, E., Paciulli, M., et al. (2017). Total phenolic content, antioxidative and antidiabetic properties of coconut (Cocos nucifera L.) testa and selected bean seed coats. Italian Journal of Food Science 29(4). 741-753. https://doi.org/10.14674/IJFS-941

Ademosun, M.T., Omoba, O.S. and Olagunju, A.I., 2020. Antioxidant properties, glycemic indices, and carbohydrate hydrolyzing enzymes activities of formulated ginger-based fruit drinks. Journal of Food Biochemistry, e13324. https://doi. org/10.1111/jfbc.13324

AL-Ishaq, R.K., Abotaleb, M., Kubatka, P., Kajo, K. and Büsselberg, D., 2019. Flavonoids and their anti-diabetic effects: cellular mechanisms and effects to improve blood sugar levels. Biomolecules 9(9): 430. https://doi.org/10.3390/biom9090430

Angmo, P., Chorol, S., Namgail, D., Chaurasia, O. and Stobdan, T. 2019. Effect of maturation on phenolics and flavonoids content of greenhouse-grown beet leaf. Pharmacognosy Journal 11(5): 1010-1013. https://doi.org/10.5530/pj.2019.11.159

Assefa, S.T., Yang, E.-Y., Chae, S.-Y., Song, M., Lee, J., Cho, M.-C., et al., S. 2020. Alpha glucosidase inhibitory activities of plants with focus on common vegetables. Plants 9(1): 2. https://doi. org/10.3390/plants9010002
Cheng, C.-W., Chen, L.-Y., Chou, C.-W. and Liang, J.-Y. 2015. Investigations of riboflavin photolysis via coloured light in the nitro blue tetrazolium assay for superoxide dismutase activity. Journal of Photochemistry and Photobiology B: Biology 148: 262-267. https://doi.org/10.1016/j.jphotobiol.2015.04.028

Chuyen, H.V., Nguyen, M.H., Roach, P.D., Golding, J.B. and Parks, S.E., 2014. Gac fruit (Momordica cochinchinensis Spreng.): a rich source of bioactive compounds and its potential health benefits. International Journal of Food Science \& Technology 50(3): 567-577. https://doi.org/10.1111/ijfs.12721

Chuyen, H.V., Roach, P.D., Golding, J.B., Parks, S.E. and Nguyen, M.H., 2020. Ultrasound-assisted extraction of GAC peel: an optimization of extraction conditions for recovering carotenoids and antioxidant capacity. Processes 8(1): 8. https:// doi.org/10.3390/pr8010008

Dobrinčić, A., Repajić, M., Garofulić, I.E., Tuđen, L., DragovićUzelac, V. and Levaj, B., 2020. Comparison of different extraction methods for the recovery of olive leaves polyphenols. Processes 8(9): 1008. https://doi.org/10.3390/pr8091008

dos Santos Pereira, E., Vinholes, J.R., Camargo, T.M., Nora, F.R., Crizel, R.L., Chaves, F., et al. 2020. Characterization of araçá fruits (Psidium cattleianum Sabine): phenolic composition, antioxidant activity and inhibition of $\alpha$-amylase and $\alpha$-glucosidase. Food Bioscience 37: 100665. https://doi.org/10.1016/j. fbio.2020.100665

Guglielmetti, A., D'ignoti, V., Ghirardello, D., Belviso, S. and Zeppa, G., 2017. Optimisation of ultrasound and microwaveassisted extraction of caffeoylquinic acids and caffeine from coffee silverskin using response surface methodology. Italian Journal of Food Science 29(3): 409-423. http://orcid.org/00000002-0397-6880. https://doi.org/10.14674/IJFS-727

İşçimen, E.M. and Hayta, M.E.H.M.E.T. 2018. Optimisation of ultrasound-assisted extraction of rice bran proteins: effects on antioxidant and antiproliferative properties. Quality Assurance and Safety of Crops \& Foods 10(2): 165-174. https://doi. org/10.3920/QAS2017.1186

Karadag, A., Pelvan, E., Dogan, K., Celik, N., Ozturk, D., Akalın, K., et al. 2019. Optimisation of green tea polysaccharides by ultrasound-assisted extraction and their in vitro antidiabetic activities. Quality Assurance and Safety of Crops \& Foods 11(5): 479-490. https://doi.org/10.3920/QAS2019.1579

Kha, T.C., Nguyen, M.H., Roach, P.D., Parks, S.E. and Stathopoulos, C., 2013. Gac fruit: nutrient and phytochemical composition, and options for processing. Food Reviews International 29(1): 92-106. https://doi.org/10.1080/87559129.2012.692141

Mogole, L., Omwoyo, W. and Mtunzi, F., 2020. Phytochemical screening, anti-oxidant activity and $\alpha$-amylase inhibition study using different extracts of loquat (Eriobotrya japonica) leaves. Heliyon 6(8): e04736. https://doi.org/10.1016/j.heliyon.2020.e04736

Moreira, S.A., Alexandre, E.M., Pintado, M. and Saraiva, J.A., 2019. Effect of emergent non-thermal extraction technologies on bioactive individual compounds profile from different plant materials. Food Research International 115: 177-190. https://doi. org/10.1016/j.foodres.2018.08.046

Munekata, P.E., Alcántara, C., Žugčić, T., Abdelkebir, R., Collado, M.C., García-Pérez, J.V., et al. 2020. Impact of 
ultrasound-assisted extraction and solvent composition on bioactive compounds and in vitro biological activities of thyme and rosemary. Food Research International 134: 109242. https://doi. org/10.1016/j.foodres.2020.109242

Nagarani, G., Abirami, A. and Siddhuraju, P., 2014. A comparative study on antioxidant potentials, inhibitory activities against key enzymes related to metabolic syndrome, and anti-inflammatory activity of leaf extract from different Momordica species. Food Science and Human Wellness 3(1): 36-46. https://doi. org/10.1016/j.fshw.2014.02.003

Ng, Z.X. and See, A.N., 2019. Effect of in vitro digestion on the total polyphenol and flavonoid, antioxidant activity and carbohydrate hydrolyzing enzymes inhibitory potential of selected functional plant-based foods. Journal of Food Processing and Preservation 43(4): e13903. https://doi.org/10.1111/jfpp.13903

Ngamsuk, S., Huang, T.-C. and Hsu, J.-L., 2019. Determination of phenolic compounds, procyanidins, and antioxidant activity in processed Coffea arabica L. leaves. Foods 8(9): 389. https://doi. org/10.3390/foods8090389

Nguyen, V., Nguyen, M., Tran, Q., Thinh, P., Bui, L., Le, T., et al. 2020. Effect of extraction solvent on total polyphenol content, total flavonoid content, and antioxidant activity of soursop seeds (Annona muricata L.). IOP Conference Series Materials Science and Engineering (MS\&E) 736(2): 022063. https://doi. org/10.1088/1757-899X/736/2/022063

Özcan, K., 2020. Antibacterial, antioxidant and enzyme inhibition activity capacities of Doronicum macrolepis (FREYN \& SINT): an endemic plant from Turkey. Saudi Pharmaceutical Journal 28(1): 95-100. https://doi.org/10.1016/j.jsps.2019.11.010

Patsilinakos, A., Ragno, R., Carradori, S., Petralito, S. and Cesa, S., 2018. Carotenoid content of Goji berries: CIELAB, HPLC-DAD analyses and quantitative correlation. Food Chemistry 268: 49-56. https://doi.org/10.1016/j.foodchem.2018.06.013

Proença, C., Freitas, M., Ribeiro, D., Oliveira, E.F., Sousa, J.L., Tomé, S.M., et al. 2017. $\alpha$-Glucosidase inhibition by flavonoids: an in vitro and in silico structure-activity relationship study. Journal of Enzyme Inhibition and Medicinal Chemistry 32(1): 1216-1228. https://doi.org/10.1080/14756366.2017.1368503

Roukas, T. and Kotzekidou, P., 2020. Pomegranate peel waste: a new substrate for citric acid production by Aspergillus niger in solid-state fermentation under non-aseptic conditions. Environmental Science and Pollution Research 27: 1310513113. https://doi.org/10.1007/s11356-020-07928-9
Shimada, A., Ueno, H., Inagaki, M. and Yoshimitsu, H., 2020. Comparative studies of the biological activities of selected herbal extracts and phenolic compounds isolated from Rosa gallica. Zeitschrift für Naturforschung C 75(1-2): 31-39. https://doi. org/10.1515/znc-2019-0117

Shori, A.B., 2020. Proteolytic activity, antioxidant, and $\alpha$-amylase inhibitory activity of yogurt enriched with coriander and cumin seeds. LWT-Food Science and Technologyv 138: 109912. https://doi.org/10.1016/j.lwt.2020.109912

Singleton, V.L. and Rossi, J.A., 1965. Colorimetry of total phenolics with phosphomolybdic-phosphotungstic acid reagents. American Journal of Enology and Viticulture 16(3): 144-158.

Stephenie, S., Chang, Y.P., Gnanasekaran, A., Esa, N.M. and Gnanaraj, C., 2020. An insight on superoxide dismutase (SOD) from plants for mammalian health enhancement. Journal of Functional Foods 68: 103917. https://doi.org/10.1016/j. jff.2020.103917

Surin, S., You, S., Seesuriyachan, P., Muangrat, R., Wangtueai, S., Jambrak, A.R., et al. 2020. Optimization of ultrasonicassisted extraction of polysaccharides from purple glutinous rice bran (Oryza sativa L.) and their antioxidant activities. Scientific Reports 10(1): 1-10. https://doi.org/10.1038/ s41598-020-67266-1

Tan, Y., Chang, S.K. and Zhang, Y., 2017. Comparison of $\alpha$-amylase, $\alpha$-glucosidase and lipase inhibitory activity of the phenolic substances in two black legumes of different genera. Food Chemistry 214: 259-268. https://doi.org/10.1016/j.foodchem.2016.06.100

Tian, J., Muhammad, S., Chen, A., Chen, P., Wang, J., Yang, C., et al. 2019. An experimental study exploring the influencing factors for ultrasonic-assisted extraction of flavonoid compounds from leaves of Amorpha fruticosa L. Journal of Forestry Research 30(5): 1735-1741. https://doi.org/10.1007/s11676-019-00931-y

Veiga, M., Costa, E.M., Silva, S. and Pintado, M., 2020. Impact of plant extracts upon human health: a review. Critical Reviews in Food Science and Nutrition 60(5): 873-886. https://doi.org/10.1 080/104.08398.2018.1540969

Yu, J.S., Roh, H.-S., Lee, S., Jung, K., Baek, K.-H. and Kim, K.H., 2017. Antiproliferative effect of Momordica cochinchinensis seeds on human lung cancer cells and isolation of the major constituents. Revista Brasileira de Farmacognosia 27(3): 329-333. https://doi.org/10.1016/j.bjp.2017.02.002 